\title{
Equity, Listening, and the Transference of Power in Design-Driven Healthcare Innovation
}

\author{
Matthew Manos \\ University of Southern California \\ verynice
}

Looking to transition towards health equity, the American Heart Association worked with a design strategy consultancy, verynice, on the development of a toolkit for human-centered innovation. Professor Matthew Manos of the USC Iovine and Young Academy led a group of students on a residential experience in Dallas that leveraged the toolkit to better understand the social determinants of health. Since then, the toolkit has since been applied to several residential experiences in the school. This paper explores the application of this toolkit in an educational environment for teaching students how to listen to community needs, and suspend their bias.

Keywords: Design Research, Design Education, Social Impact

\section{THE CHALLENGE: CREATING A TOOLKIT CENTERED AROUND "LISTENING"}

According to the Center for Disease Control, the "factors that influence the socioeconomic position of individuals and groups within industrial societies also influence their health." (U.S. Department of Health and Human Services Centers for Disease Control and Prevention, 2013). Further, according to the American Journal of Preventive Medicine, over a period of 40 years, people living in urban environments have shown a significantly more rapid growth in life expectancy than their rural counterparts. Specifically, this gap is found to be attributed to higher rates of cardiovascular disease among other issues (Stephens, 2014). The American Heart Association (AHA) has almost 100 years of experience uncovering barriers to better health across the United States. As a national organization, the AHA has a unique challenge to represent all needs from all communities in order to fulfill a holistic mission to "be a relentless force for a world of longer, healthier lives." Some communities, especially those that are rural, can go unheard or can be inadequately addressed by solutions that don't match their circumstances. In recognition of the growing understanding of social determinants of health as well as the rural life expectancy gap, the American Heart Association needed to develop an approach that would allow them, and other mission-driven health organizations, to better understand the needs of all Americans.

Design Research and Human-Centered Design have a unique ability to serve as the connecting bridge between people and business. This is typically accomplished with an empathy-first mindset that believes impact within a community, organization, or enterprise can come upon shifting from a top-down mindset to one that is bottom-up and "people first". When compared, the promise of design research, and the gap of understanding the needs of rural and vulnerable communities in the United States reveal a unique opportunity to apply the human-centered design process to the outreach and health equity initiatives of the 
American Heart Association. As a result, the AHA collaborated with my design strategy consultancy, verynice, in 2017, in order to develop a creative methodology that could build capacity for Design Research and "Listening" within and beyond the organization. The goal of this toolkit is threefold:

Understand the assets, needs, and circumstances of rural communities.

Align scientific understanding with a more human-centered perspective.

Build staff capacity in qualitative design research and rapid ethnographic methodologies.

In addition, it was important to both the client and the consultancy that the resulting methodology be made publicly available for any individual or organization tackling similar issues. While counterintuitive to open-source a new "trade secret" that would soon be developed, both the client and the consultancy understood the potential ripple effect of impact that could take place if the methodology were to be made openly accessible. Further, as both the lead Strategist for the development of this toolkit and an Assistant Professor and Assistant Dean at the University of Southern California, I saw a unique opportunity to take advantage of the toolkit's open access and apply it to the classroom environment. The primary goal of this application was to teach students actionable skills and approaches to suspending their bias while also learning to be collaborators with the end user as opposed to designers for the end user.

\section{THE PROCESS}

My working relationship with the AHA began in 2015. I have personally led projects with the organization related to business planning, strategic planning, and research \& development. These projects include the revitalization of the organization's "Heart Walk" experience, and the redesign of the organization's strategic value proposition. When approached to create a new toolkit for the organization that would merge the principles of design with the incredible impact of the AHA, I was thrilled.

How might we develop a design research methodology to better understand the needs of rural communities? With the primary goal of the toolkit being to design research methods and build capacity within the organization for listening skills, we began the project by doing a deep-dive into exploring "listening". To begin, we identified a series of 7 experts to interview about the art of listening. These experts included practitioners in journalism, leadership coaching, education, and social work. The interviews were synthesized and provided to the organization in the form of a series of short films. In addition to the films, we produced and moderated a panel discussion and workshop at the AHA's Los Angeles office with additional experts in listening.

Following this initial research, the team at verynice developed a draft of the design research methodology to prototype with a rural community in Salinas, California in September, 2017. This participatory workshop was held at a local community center. Over the course of 2 hours, our facilitators led 14 participants through a series of activities. From the workshop, we made adjustments to the flow of activities as well as the instructions, and came to a finalized model and toolkit for the organization.

\section{THE METHODOLOGY}

The methodology itself is comprised of 4 key phases including Question, Listen, Reflect, and Learn. This toolkit differs from the mainstream design process of "Empathize, Define, Ideate, Prototype, and Test" by filling a necessary gap in Design Thinking: the ability to transfer power. In Design Thinking, the end user or beneficiary is typically involved in the beginning stage (empathize), and the end phase (test). This creates a power dynamic in which the designer is the translator and author of the subject's own ideas and observations. In doing so, bias is naturally attached to the ideation and prototyping phases. Instead, with this toolkit, the user is involved throughout the entire process. In doing so, the person who is empathizing does not become a "hero", and the person who is being empathized with does not become silenced. 
FIGURE 1

FOUR KEY PHASES OF THE METHODOLOGY

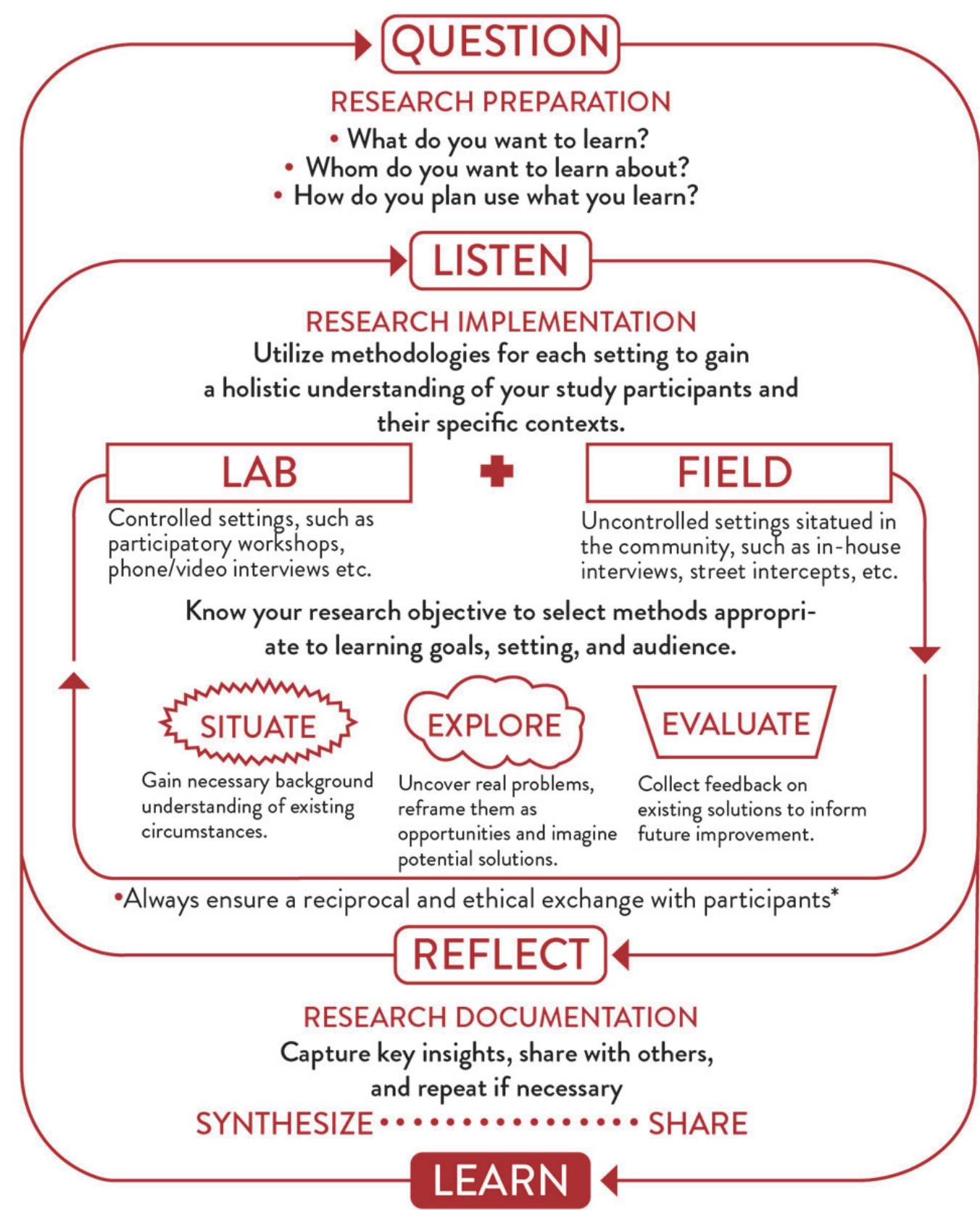

The toolkit includes the above diagram. The methodology itself is comprised of 4 key phases including Question, Listen, Reflect, and Learn. In the Listen phase, the designer identifies both the setting of their research as well as the key research objective in order to proceed and select more specific activities. The full toolkit, videos, and additional documentation is available for anyone to freely access at https://ahaislistening.tumblr.com/ (Manos, 2017)

\section{Question}

Every great study starts with great questions. The first phase of the methodology consists of research preparation. In this phase, we reflect on what we want to learn, whom we plan to learn about, and how we 
plan to use what we learn. We then share these assumptions with experts in the community in order to validate or revise.

\section{Listen}

The best way to learn about others is by listening to them. The trick is being able to hear what you need to learn for the purpose of the study. The second phase of our methodology uncovers answers to the research questions by implementing the research. The toolkit includes scenarios and suggested research activities for 3 research objectives (situate, explore, evaluate), and 2 research settings (lab, field). While the lab setting is a controlled environment such as a participatory workshop or phone/video interview, the field setting is uncontrolled, with interviews and interventions taking place in the community itself. The objective to "situate" is most appropriate in a scenario in which the researcher aims to gain a necessary background of understanding within a community. The objective to "explore" leads to the uncovering of real problems, re-framed as opportunities. Finally, the objective to "evaluate" focuses on collecting feedback on previously developed solutions. The methodology recommends a blended approach as it pertains to setting, but a specific approach as it pertains to objective.

\section{Reflect}

The reflection phase is about making sense of what was heard. This is done by way of reporting out on findings to the larger research group and community, or through written synthesis.

\section{Learn}

In this phase, the researcher reflects on the work and puts newly gained understanding into action. The researcher thinks about the observations, interpretations, and implications, and what those mean for the greater goal and impact of the study.

Upon completion of the toolkit's development, verynice hosted a training with the AHA in order to onboard all staff working in health equity and community impact. The training was recorded so as to allow those who could not attend to have equal access to the content. The organization continues to use the tool in rural and vulnerable communities in order to gain key insights for the ways in which they can best assist as a national organization.

\section{APPLYING THE TOOLKIT TO THE USC IOVINE AND YOUNG ACADEMY'S PROFESSIONAL PRACTICES RESIDENTIAL EXPERIENCES}

Shortly after the methodology was made available online for anyone to access and use freely, our toolkit was incorporated into a course at the Santa Monica College, a public, two-year, community college in Santa Monica, California, United States. The course focused on teaching students the design thinking approach and mindset. Santa Monica College students leveraged this toolkit to conduct field research for a group project focused on the issue of food deserts in Southern California.

After hearing of the success of the toolkit when applied to the Santa Monica College, I became intrigued to apply the toolkit as the centerpiece for a class of my own. At the USC Iovine and Young Academy, we have an online graduate program, the Masters of Science in Integrated Design, Business, and Technology (MSIDBT). While primarily online, the MSIDBT also includes a series of Professional Practices Residential (PPR) experiences, that bring students on-the-ground into an organization or enterprise to take on a challenge over the course of 5 intensive days. The purpose of the course is to give students the opportunity to work on a design research challenge with a real organization facing a real challenge. When asked to lead a PPR focused on healthcare, I immediately thought of the AHA as a perfect partner.

With 19 graduate students, we embarked on a journey to the AHA's headquarters in Dallas, Texas, in order to leverage the toolkit in local communities to assist the organization in identifying new 
partnerships and opportunities for impact. Students were provided the following prompt upon their arrival in Dallas, Texas:

For nearly 100 years, the American Heart Association has been fighting heart disease and stroke, striving to save and improve lives. With the unique mission "to be a relentless force for a world of longer, healthier lives", the American Heart Association has developed a range of approaches to driving innovation from an equity first perspective at a national and community level. In this Professional Practices Residential, graduate students in the Iovine and Young Academy are challenged to leverage Design Research methodologies in order to conduct field work in local Dallas communities. Inspired by their field work, students will enter two intensive hack-a-thon sessions in order to synthesize, ideate, and further develop a series of strategic recommendations for design-driven innovation opportunities that can inspire future work by the organization at the local level.

In addition, students were assigned to work with a partner organization in one of 4 Dallas communities in order to minimize the time required to understand the nuances and environment. Finally, students were trained on various methodologies and activities from the Design Research toolkit that would be specifically relevant in the context of the communities they were assigned. The experience resulted in tangible strategic advice for the organization's various non-profit partners including business model design for a local community garden, a concept for a community mural, and curriculum for an after-school program.

Our next Professional Practices Residential experience was in partnership with the Children's Hospital of Los Angeles (CHLA). CHLA has a history that spans over 100 years, and offers 350+ pediatric programs and offerings to meet the needs of their patients. At the commencement of this residential, students were trained on the toolkit, and were provided the following vision statement:

OUR VISION is to enable our patients with diabetes and their families to lead healthy, thriving lives with minimal disruption and inconvenience. We want our program to be adaptable to a patient's developmental stage and life experiences.

Guided by this vision, students engaged in a series of interviews, interventions, and observational studies in order to clarify their understanding of the current patient experience. Following this series of ethnographic studies, students developed strategic recommendations and product design concepts for the hospital's innovation team to carry forward. This included a chatbot that would reduce emergency hotline calls, a mobile health clinic to reduce the pain of traffic for patients, and a gamified on-boarding experience for new patients.

\section{NEXT STEPS AND INITIAL CONCLUSIONS}

Based on the success of the toolkit's application to the Professional Practices Residential experiences, the tool is in the process of being implemented into the core curriculum of each residential experience in the MSIDBT program as well as an undergraduate course on Design Consulting/Design Strategy. The university is currently planning to work with the AHA for another 2 experiences in the Summer 2019 and Fall 2019 semesters to take place in Boston and Puerto Rico. The following are 3 key learnings from the engagements to-date.

\section{What People Say Is Often Different Than What People Do.}

Limiting the research process to phone interviews or surveys is limiting. By leveraging design-driven techniques such as drawing exercises, and by learning how to pay attention to body language, we drew more comprehensive research results that led to more impactful recommendations for the clients. For example, in a class we recently had students interview their grandparents about the process of using prescription pills. One student claimed their grandmother had no issue with the pill bottle itself, but after further observation, the student learned this was due to her "hack" in which she removed the caps of the pill bottles and replaced them with plastic wrap. 


\section{By Having an On-the-ground Partner/Client, Student Work Can Be Less Disruptive.}

It can be very disruptive to a community when a group of students enter without context and begin interviewing and speaking to as many people as they can. By developing on-the-ground partnerships with organizations that work in the space day-in and day-out, we were able to earn buy-in more quickly. Further, by incorporating the end user throughout the design process, we can more successfully design in an manner that is not filtered through our own biases and aspirations.

\section{Shift Focus in Design for Social Impact.}

In teaching design research practices in the classroom, there is a great opportunity to focus that work by assisting organizations such as the American Heart Association and the Children's Hospital of Los Angeles who do incredibly impactful work with significantly less resources than many other private sector enterprises. For example, in previous institutions that I taught in, we would create speculative client projects. Instead of the speculative approach, we are able to have the same rigor of project, but make it "real" by reaching out to the community in order to turn those speculative projects into challenges for our students to contribute to.

\section{REFERENCES}

Manos, M. (2017, September 13). AHA Design Research Toolkit. Retrieved April 19, from https://www.slideshare.net/secret/LfCePfW3aacrzy

Stephens, S. (2014, January 23). Gap in Life Expectancy Between Rural and Urban Residents Is Growing. Center for Advancing Health. Retrieved February 11, from http://www.cfah.org/hbns/2014/gapin-life-expectancy-between-rural-and-urban-residents-is-growing

U.S. Department of Health and Human Services Centers for Disease Control and Prevention. (2013, November 22). Morbidity and Mortality Weekly Report. Vol. 62, No. 3. Center for Disease Control. Retrieved February 11, from https://www.cdc.gov/mmwr/pdf/other/su6203.pdf 